\title{
PENGARUH PERLAKUAN ALKALI PADA REKAYASA BAHAN KOMPOSIT BERPENGUAT SERAT RAMI BERMATRIK POLIESTER TERHADAP KEKUATAN MEKANIS
}

\author{
Agus Hariyanto \\ Teknik Mesin Universitas Muhammadiyah Surakarta \\ Jl. A.Yani Tromol Pos I Pabelan, Kartosura \\ email:agus_haryanto@ums.ac.id
}

\begin{abstract}
ABSTRAK
Tujuan penelitian ini adalah menyelidiki pengaruh waktu perlakuan alkali terhadap peningkatan kekuatan bending dan impak komposit berpenguat serat rami bermatrix poliester. Mekanisme perpatahan diamati dengan photo makro.

Bahan utama penelitian adalah serat rami, resin unsaturated polyester 157 BQTN. Hardener yang digunakan adalah MEKPO dengan konsentrasi 1\%. Komposit dibuat dengan metode cetak tekan (press mold). Komposit terdiri dari serat rami acak. Fraksi volume serat komposit adalah 40\%. Perlakuan alkali (NaOH) 5\% dengan variasi lama perendaman 2, 4, 6, 8 jam. Spesimen dan prosedur pengujian bending dan impak izod mengacu pada standart ASTM D 790 dan ASTM D 5941. Penampang patahan dilakukan foto makro untuk mengidentifikasi pola kegagalannya.

Hasil penelitian ini menunjukkan bahwa penambahan waktu perlakuan alkali (NaOH) 5\% menurunkan kekuatan bending dan kekuatan impak secara signifikan pada komposit. Mekanisme patahan terjadi patah getas akibat kekuatan bending dan impak, diawali oleh tahapan pola kegagalan tarik pada komposit sisi bawah dan kegagalan tekan pada komposit sisi atas, kegagalan fiber pull out.
\end{abstract}

Kata Kunci: komposit, perlakuan alkali, kekuatan bending kekuatan impak mekanisme kegagalan.

\section{PENDAHULUAN}

Penggunaan bahan komposit sebagai alternatif pengganti bahan logam dalam bidang rekayasa sudah semakin meluas, yang tidak hanya sebagai panel di bidang transportasi tetapi juga merambah pada bidang lainnya seperti properti dan arsitektur. Hal ini dikarenakan oleh adanya keuntungan penggunaan bahan komposit seperti konstruksi menjadi lebih ringan, tahan korosi dan kekuatannya dapat didesain sesuai dengan arah pembebanan. Fokus pemilihan bahan yang tepat untuk suatu konstruksi menuntut sebuah kepastian tentang material penyusun yang tepat pula. Tuntutan fungsi panel saat ini tidaklah hanya sebatas kekuatan mekanik saja, tetapi juga sifat fisisnya (Peijs, 2002). Dalam penelitian ini ditekankan pada penyelidikankekuatan bending dan kekuatan impak bermatrix poliester serta pola kegagalannnya. Penggunaan kembali serat alam, dipicu oleh adanya regulasi tentang persyaratan habis pakai (end of life) produk komponen otomotif bagi negara-negara Uni Eropa dan sebagian Asia. Bahkan sejak tahun 2006, negaranegara Uni Eropa telah mendaur ulang 80\% 
komponen otomotif, dan akan meningkat menjadi $85 \%$ pada tahun 2015. Di Asia khususnya di Jepang, sekitar 88\% komponen otomotif telah di daur ulang pada tahun 2005 dan akan meningkat pada tahun 2015 menjadi 95\%. Pengembangan teknologi komposit berpenguat serat alam sejalan dengan kebijakan pemerintah untuk menggali potensi local genius yang ada. Hal ini tentu akan mampu meningkatkan pemberdayaan sumber daya alam lokal yang dapat diperbaharui (Jamasri, 2008). Lebih lanjut lagi, perkembangan teknologi komposit pun mengalami perkembangan yang sangat dinamis dan cepat. Saat ini material penguat komposit mengalami pergeseran dari penggunaan serat sintetis menuju serat alam. Hal ini disebabkan oleh adanya efek limbah serat sintetis yang tidak dapat terurai secara alami. Indonesia sebagai negara tropis menghasilkan berbagai jenis serat alam seperti kenaf, rami, abaca, agave, dan lain sebagainya. Produksi serat rami di dunia dapat dikatakan cukup besar, 400.000 ton per tahun sampai saat ini kekurangan pasokan sebesar 270.000 ton per tahun, dengan total penawaran 130.000 ton. Dari hasil penelitian, serat rami di Indonesia kualitasnya mampu bersaing dengan serat rami dari Cina, Brazil, Filipina, Taiwan, Korea, Komboja, Thailand dan Vietnam. Dengan demikian pengembangan tanaman ini memiliki prospek yang sangat cerah, karena sampai saat ini Indonesia merupakan potensi yang besar untuk menggerakkan ekonomi rakyat melalui perekonomian pedesaan (Sudiro.D., 2004). Dengan demikian, pemanfaatan serat rami sebagai penguat panel komposit merupakan salah satu solusi yang tepat untuk meningkatkan nilai teknologi dan ekonomi serat rami.

Kajian riset bahan panel komposit kini banyak dikonsentrasikan pada studi sifat mekanis dan fisis. Namun, penggunaan komposit sebagai panel tidak lepas dari tuntutan keselamatan pengguna. Salah satu sifat panel yang mendukung keselamatan yang baik adalah panel yang sudah diketahui kekuatan mekanisnya. Sebagai contoh, penggunaan bahan hasil industri yang diketahui spesifikasinya. Seiring dengan konsep rancangan bahan komposit serat rami bermatrik poliester yang akan digunakan sebagai panel, maka sifat mekanis yang baik diperlukan sebagai salah satu parameter yang menentukan keselamatan pemakaian.

Pentingnya analisis mekanis ini didasarkan pada penentuan kekuatan desain struktur untuk memberikan keyakinan atas keselamatan pemakaian. Uraian tersebut di atas menunjukkan bahwa kajian riset panel menjadi penting untuk di kaji. Penelitian ini bertujuan untuk menyelidiki sifat mekanis bending dan impak komposit berpenguat serat rami dengan matrik unsaturated polyester. Penelitian ini bertujuan untuk menyelidiki sifat mekanis bending dan impak komposit berpenguat serat rami dengan matrik unsaturated polyester. Penelitian ini dilakukan dalam rangka memperoleh solusi pemilihan material struktur komposit ataupun solusi alternatif rancangan struktur komposit yang dalam aplikasinya erat kaitannya dengan keamanan/ keselamatan pemakaian.

\section{TINJAUAN PUSTAKA}

Pada penelitian pendahuluan, Nugraha, dkk (2005) melakukan perlakuan kimia serat alam ramie (Boehmeria Nivea) yang menunjukkan kekuatan tarik serat dapat ditingkatkan sehingga akan mampu menjadi alternatif media penguatan pada bahan komposit polimer penguatan serat alam. Marsyahyo, dkk (2005) membandingkan kekuatan tarik komposit polimer epoxy dan polyester dengan penguatan serat alam dari beberapa tanaman tropis tanpa mengalami perlakuan ( green fibers) dengan hasil bahwa serat ramie memiliki penguatan relatif paling tinggi dibandingkan serat alam daun nanas, pelepah pisang, kenaf, bambu, serbuk tempurung kelapa dan agel (agave).

Perlakuan serat kenaf kontinyu dan acak dengan $5 \% \mathrm{NaOH}$ yang direndam pada suhu $19 \pm 2{ }^{\circ} \mathrm{C}$ selama 48 jam menyebabkan permukaan serat menjadi lebih kasar karena lapisan lignin dan kotoran di bagian permukaan serat hilang. Topografi permukaan serat yang kasar akan menghasilkan mechanical interlocking yang lebih baik dengan matrik. Perlakuan $5 \% \mathrm{NaOH}$ serat kenaf kontinyu selama 
48 jam masing-masing mempengaruhi elastisitas bending, kekuatan bending, dan harga impak komposit kenaf-polyester pada $\mathrm{V}_{\mathrm{f}}=64 \%$, yaitu $13 \mathrm{GPa}, 123 \mathrm{MPa}$, dan $75 \mathrm{KJ} / \mathrm{m}^{2}$. Hasil tersebut menunjukkan bahwa perlakuan serat selama 48 jam menurunkan elastisitas bending sebesar 3\%, kekuatan bending sebesar $3 \%$, dan harga impak sebesar $3 \%$, dibandingkan tanpa perlakuan alkali (Azis dkk, 2003).

\section{METODE PENELITIAN}

Bahan utama penelitian adalah serat rami acak dengan massa jenis $1,53 \mathrm{gr} / \mathrm{cm}^{3}$, unsaturated poliester type $157 \mathrm{BQTN}$, hardener MEKPO dengan kadar 1\%. Serat ramie yang digunakan dengan perlakuan .alkali $(\mathrm{NaOH})=$ $5 \%$ dengan variasi lama perendaman 2, 4, 6 , dan 8 jam.

Pembuatan komposit dibuat dengan metode cetak tekan (press mold). Variabel penelitian ini adalah fraksi volume serat ramie sebesar $40 \%$. Pengujian bending dilakukan dengan three point bending method, seperti ditunjukkan pada gambar 1 . Spesimen dan metode pengujiannya mengacu pada standar ASTM D 790-02.
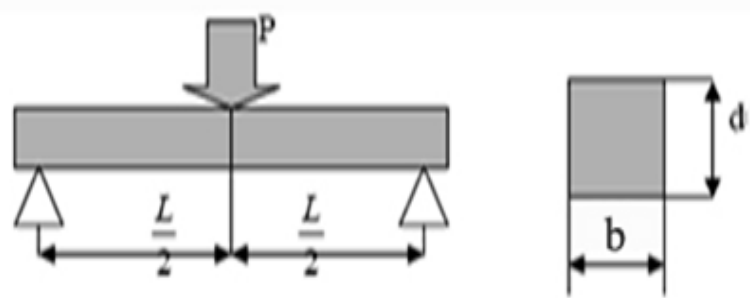

Gambar 1. Metode Pengujian Three Point Bending (ASTM D790)

Kekuatan bendingnya dapat dihitung dengan persamaan berikut (ASTM, D 790):

$$
\sigma_{b}=\frac{3 P L}{2 b d^{2}}
$$

dengan catatan; $\mathrm{P}=$ beban $(\mathrm{N}), \mathrm{L}=$ panjang span $(\mathrm{mm}), \mathrm{b}=$ lebar $(\mathrm{mm})$, dan d = tebal $(\mathrm{mm})$. Jika defleksi maksimum yang terjadi lebih dari $10 \%$ dari jarak antar penumpu (L),

$$
\sigma_{b}=\frac{3 P L}{2 b h^{2}}\left[1+4\left(\frac{\delta}{L}\right)^{2}\right]
$$

Modulus elastisitas bendingnya dapat dirumuskan dengan persamaan :

$$
E_{b}=\frac{1}{4} \times \frac{L^{3}}{b h^{3}} \times \frac{P}{\delta}
$$

Perhitungan kekakuan bending:

$$
\mathrm{D}=\mathrm{E}_{\mathrm{b}} \times \mathrm{I} .
$$

Momen inersia untuk balok:

$$
I=\frac{b \times h^{3}}{12}
$$

Rumusan untuk menghitung besarnya energi yang terserap komposit pada pengujian impak izot adalah (Manual book of GotechIzod Impact);

$$
E_{\text {serap }}=W R\left[(\cos \beta-\cos \alpha)-\left(\cos \alpha^{!}-\cos \alpha\right)\left\langle\frac{\alpha+\beta}{\alpha+\alpha^{!}}\right\rangle\right]
$$

inergi terserap pada pengujian impak adalah Shackelford, 1992):

$$
E_{\text {serap }}=W R[\operatorname{Cos} \beta-\operatorname{Cos} \alpha]
$$

Dengan catatan; $\mathrm{E}_{\text {serap }}=$ energi terserap (J), W = berat pendulum $(\mathrm{N}), \mathrm{R}=$ panjang lengan pendulum $(\mathrm{m}), ?=$ sudut pantul pendulum $\left({ }^{\circ}\right)$, dan $?=$ sudut ayun pendulum $\left({ }^{0}\right)$. Besarnya kekuatan impak dapat dihitung dengan persamaan (Shackelford, 1992);

$$
\text { Kekuatan Impak }=\mathrm{HI}=\frac{E_{\text {serap }}}{A}
$$

dengan $\mathrm{A}$ = luas penampang komposit. 


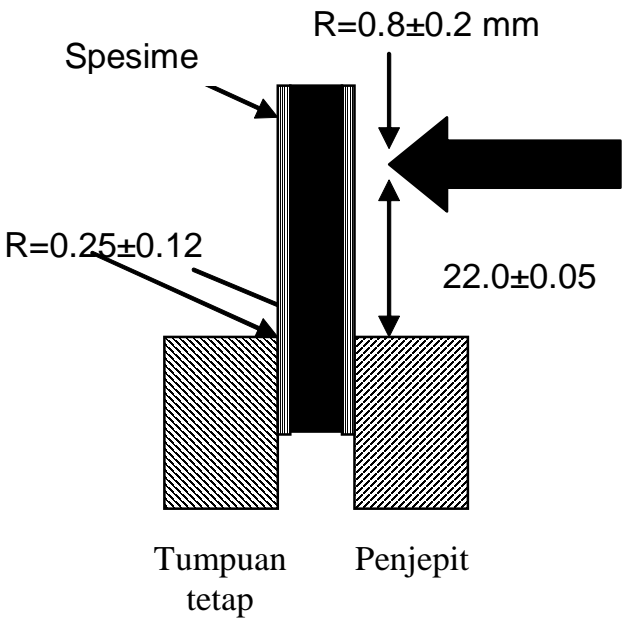

\section{Gambar 2. Metoda Pengujian Impak Izod Skin (ASTM D 5941)}

Penampang patahan spesimen uji dilakukan foto makro untuk mengidentifikasi pola kegagalannya.

\section{HASIL DAN PEMBAHASAN}

1. Uji bending komposit berpenguat serat rami perlakuan $\mathrm{NaOH}=\mathbf{5 \%}$.

Pengujian bending komposit berpenguat serat rami perlakuan $\mathrm{NaOH} 5 \%$ variasi lama perendaman 2, 4, 6, 8 jam dilakukan dengan acuan pengujian sesuai standar ASTM D 790. Data hasil pengujian bending komposit skin berpenguat serat rami ditunjukkan sesuai tabel 1 .

Tabel 1. Data Hasil Pengujian Bending Komposit Skin Berpenguat Serat Rami

\begin{tabular}{|c|c|c|}
\hline Perlakuan & $\begin{array}{c}\text { Fraksi } \\
\text { Volume } \\
\left.\text { Serat ( } \mathrm{V}_{\mathrm{f}}\right)\end{array}$ & $\begin{array}{c}\text { Kekuatan } \\
\text { Bending } \\
\text { rata-rata } \\
\left(\mathrm{N} / \mathrm{mm}^{2}\right)\end{array}$ \\
\hline $\begin{array}{c}\mathrm{NaOH} \mathrm{5 \%} \\
2 \text { jam }\end{array}$ & $40 \%$ & 143.96 \\
\hline $\begin{array}{c}\text { NaOH 5\% } \\
4 \text { jam }\end{array}$ & $40 \%$ & 46.02 \\
\hline $\begin{array}{c}\mathrm{NaOH} 5 \% \\
6 \text { jam }\end{array}$ & $40 \%$ & 123.26 \\
\hline $\begin{array}{c}\text { NaOH } 5 \% \\
8 \text { jam }\end{array}$ & $40 \%$ & 86.76 \\
\hline
\end{tabular}

Dari hasil pengujian bending komposit skin dengan $\mathrm{V}_{\mathrm{f}}=40 \%$ konstan diperoleh kekuatan bending tertinggi pada komposit dengan perlakuan alkali 5\% lama perendaman 2 jam sebesar $143.96 \mathrm{~N} / \mathrm{mm}^{2}$. Terjadinya penurunan kekuatan serat akibat perendaman yang terlalu lama. Sehingga, dengan mengetahui nilai optimasi tegangan tarik serat tunggal tertinggi dicapai pada perlakuan alkali 5\% selama 2 jam dan pengaruh perbesaran diameter serat - serat kekasaran permukaan serat mengakibatkan mechanical interlocking yang kuat antara matrik dan serat. Hal inilah yang menyebabkan nilai optimasi kekuatan bending tertinggi dicapai pada komposit perlakuan $\mathrm{NaOH}$ 5\% selama 2 jam. Adapun grafik kekuatan bending komposit dengan $\mathrm{V}_{\mathrm{f}} 40 \%$ terhadap variasi lama perlakuan alkali sesuai gambar 3 .

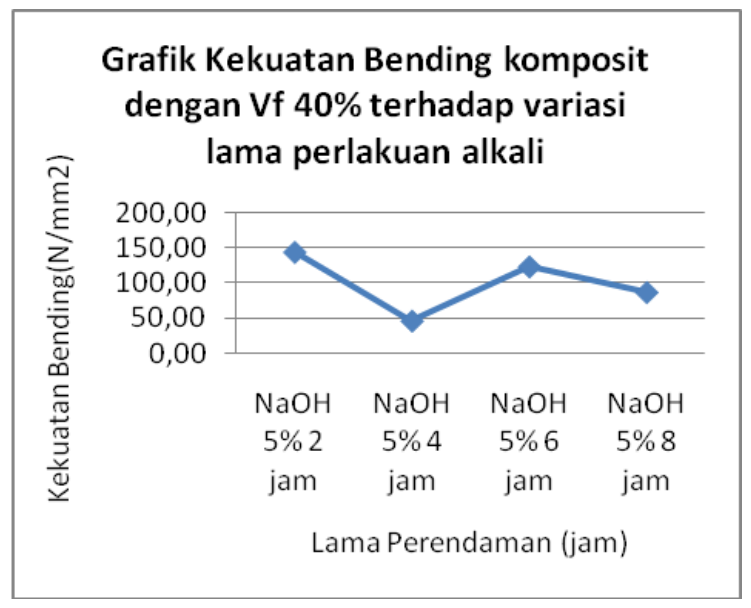

\section{Gambar 3.Grafik Kekuatan Bending Komposit dengan $V_{f} 40 \%$ terhadap Variasi Lama Perlakuan Alkali}

\section{Uji impak komposit berpenguat serat} ramie perlakuan $\mathrm{NaOH} 5 \%$.

Pengujian impak komposit skin berpenguat serat rami merupakan pengujian mekanis yang berguna untuk mengetahui kekuatan impak komposit tersebut. Sampel spesimen dipersiapkan dengan perlakuan alkali variasi waktu perendaman serat (2, 4, 6, 8 jam) dengan $\mathrm{V}_{\mathrm{f}}$ konstan 40\%. Data hasil pengujian impak komposit skin berpenguat serat rami ditunjukkan sesuai tabel 2. 
Tabel 2. Data Hasil Pengujian Impak Komposit Skin Berpenguat Serat Rami

\begin{tabular}{|c|c|c|}
\hline Perlakuan & $\begin{array}{c}\text { Fraksi } \\
\text { Volume } \\
\text { Serat (Vf) }\end{array}$ & $\begin{array}{c}\text { Kekuatan } \\
\text { Impak } \\
\text { Rata-rata } \\
\left(\mathrm{J} / \mathrm{mm}^{2}\right)\end{array}$ \\
\hline $\begin{array}{c}\text { NaOH 5\% } \\
2 \text { jam }\end{array}$ & $40 \%$ & 1.167 \\
\hline $\begin{array}{c}\text { NaOH 5\% } \\
4 \text { jam }\end{array}$ & $40 \%$ & 1.067 \\
\hline $\begin{array}{c}\text { NaOH 5\% } \\
6 \text { jam }\end{array}$ & $40 \%$ & 1.067 \\
\hline $\begin{array}{c}\text { NaOH 5\% } \\
8 \text { jam }\end{array}$ & $40 \%$ & 1.033 \\
\hline
\end{tabular}

Dari hasil pengujian impak sesuai tabel 2, kekuatan impak tertinggi terjadi pada komposit dengan perlakuan allkali 5\% selama 2 jam yaitu sebesar $1.167 \mathrm{~J} / \mathrm{mm}^{2}$. Hal ini menunjukkan adanya sifat propertis dasar serat yang jauh lebih kuat pada perlakuan $\mathrm{NaOH} 5 \%$ selama 2 jam dan juga dengan kasarnya permukaan serat dapat menyebabkan mechanichal interlocking yang kuat antara matrik dan serat pada komposit tersebut. Sebaliknya, penurunan kekuatan impak disebabkan akibat sifat propertis dasar serat yang menurun kekuatannnya dan juga akibat ketidaksempurnaan ikatan antara matrik dan serat yang menyebabkan lemahnya mechanical inter-

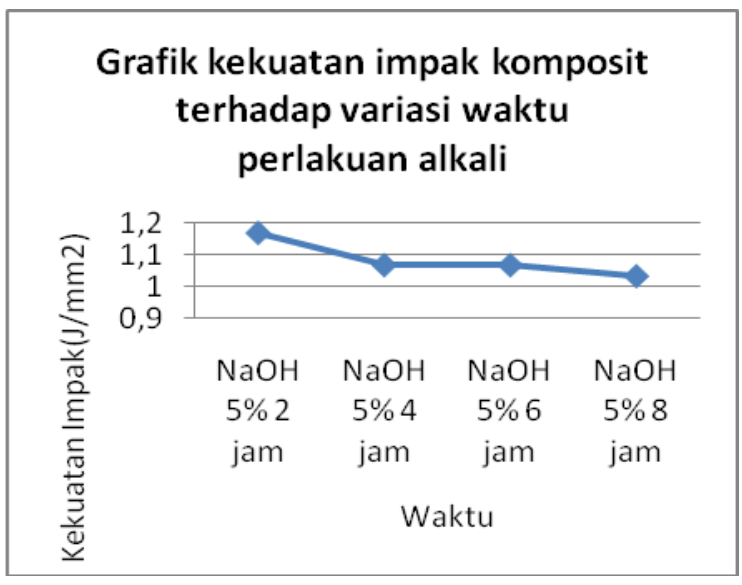

\section{Gambar 4.Grafik Kekuatan Impak terhadap Variasi Waktu Perlakuan NaOH 5\%}

locking antar serat dan matrik. Grafik kekuatan impak terhadap variasi waktu perlakuan $\mathrm{NaOH}$ $5 \%$ seperti pada gambar 4 . Bila ditinjau dari segi kekuatan impak, penambahan waktu perlakuan menurunkan kekuatan impak komposit. Kekuatan impak komposit yang diperkuat serat ramie acak memiliki sifat keuletan bahan ini dapat dikatakan lebih baik.

\section{Analisis Pola Kegagalan Bending dan Impak}

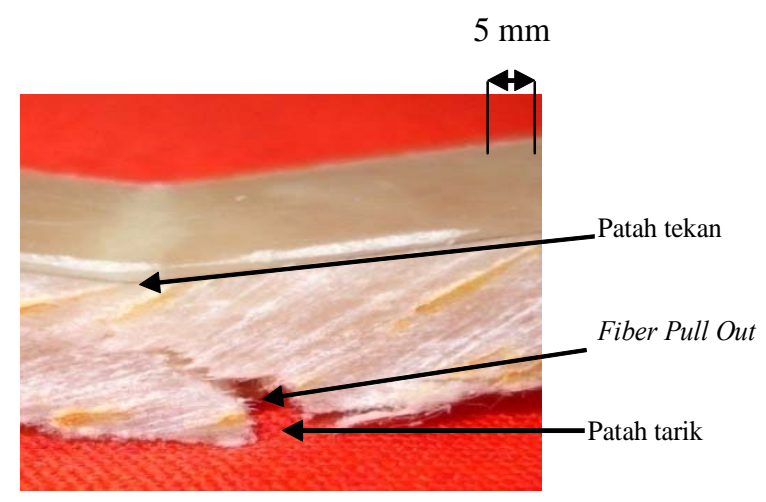

\section{Gambar 5. Penampang Patahan Kegagalan Bending dengan $V_{f} 40 \%$ Waktu Alkali 2 jam}

Kegagalan bending komposit ditunjukkan pada gambar 5. Secara umum, pola kegagalan diawali dengan retakan pada komposit skin yang menderita tegangan tarik pada sisi bawah dan tegangan tekan pada sisi atas. Kemudian, beban bending tersebut didistribusikan pada skin sehingga menyebabkan mengalami kegagalan fiber pull out.

Mekanisme patahan impak ditunjukkan pada Gambar 6 terjadi karena kegagalan patah getas dan fiber pull out akibat beban berawal dari skin komposit sisi belakang (bawah). 
serat $\mathrm{V}_{\mathrm{f}}=40 \%$, perlakuan alkali $(\mathrm{NaOH})$ serat rami $(0,2,4,6$, dan,8 jam) menghasilkan kekuatan mekanis terbaik dengan perendaman $\mathrm{NaOH} 5 \%$ selama 2 jam sebesar 1,167 (J/mm²).

3. Tahapan pola kegagalan komposit adalah kegagalan tarik pada komposit sisi bawah dan kegagalan tekan pada komposit sisi atas, kegagalan fiber pull out. Mekanisme patahan, terjadi patah getas akibat kekuatan bending dan impak.

\section{NOTASI PERSAMAAN:}

\section{Gambar 6. Patahan Spesimen Uji Impak dengan $V_{f} 40 \%$ Waktu Alkali 2 Jam}

\section{KESIMPULAN}

1. Optimasi kekuatan mekanis terbaik dari pengujian bending bahan komposit serat rami - polyester dengan variabel fraksi volume serat $\mathrm{V}_{\mathrm{f}}=40 \%$, perlakuan alkali $(\mathrm{NaOH})$ serat rami $(0,2,4,6$, dan,8 jam) mengGagal tekan hasilkan kekuatan mekanis terbaik dengan

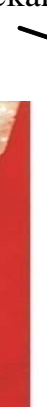

anis terbaik dari mposit serat rami ,el fraksi volume

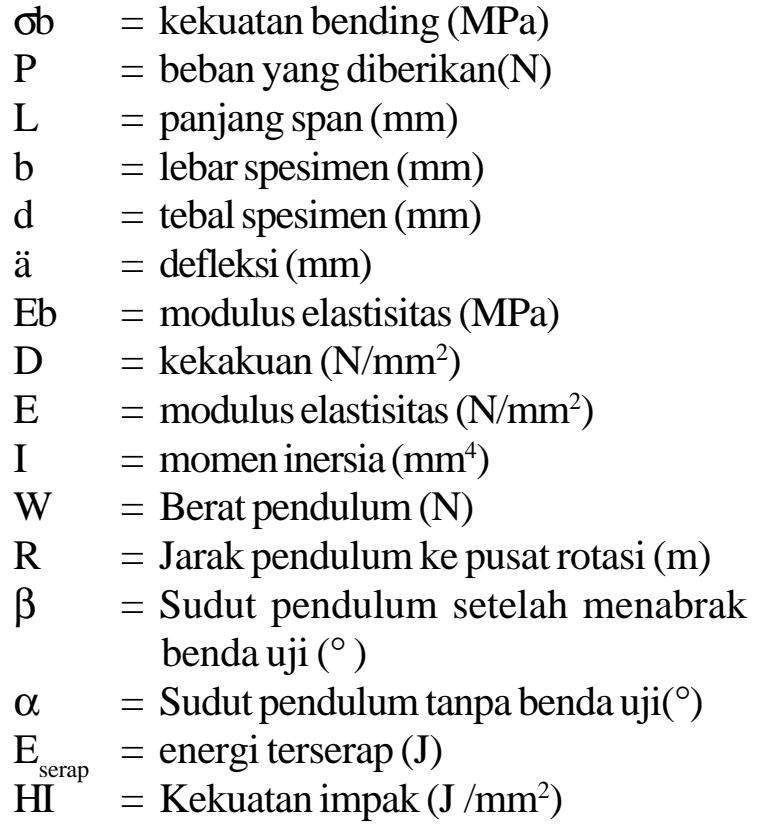

$\mathrm{P} \quad=$ beban yang diberikan $(\mathrm{N})$

$\mathrm{L} \quad=$ panjang span (mm)

$\mathrm{b} \quad=$ lebar spesimen $(\mathrm{mm})$

$\mathrm{d} \quad=$ tebal spesimen $(\mathrm{mm})$

$=\operatorname{defleksi}(\mathrm{mm})$

$\mathrm{D}=\operatorname{kekakuan}\left(\mathrm{N} / \mathrm{mm}^{2}\right)$

$\mathrm{E} \quad=$ modulus elastisitas $\left(\mathrm{N} / \mathrm{mm}^{2}\right)$

I $=$ momen inersia $\left(\mathrm{mm}^{4}\right)$

$\mathrm{W}=$ Berat pendulum $(\mathrm{N})$

$\mathrm{R} \quad=$ Jarak pendulum ke pusat rotasi (m)

$\beta=$ Sudut pendulum setelah menabrak benda uji $\left({ }^{\circ}\right)$

$\mathrm{E}_{\text {serap }}=$ energi terserap $(\mathrm{J})$

$\mathrm{HI}=\operatorname{Kekuatan} \operatorname{impak}\left(\mathrm{J} / \mathrm{mm}^{2}\right)$

\section{DAFTAR PUSTAKA}

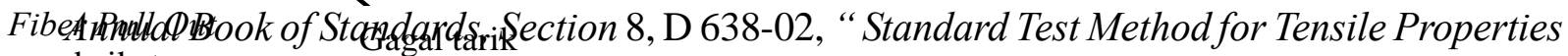
pada ikatan of Plastics", ASTM, 2002.

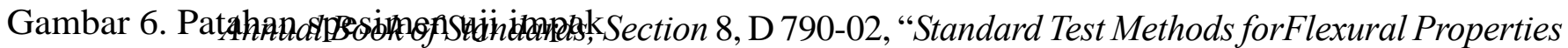
dengan $\mathrm{V}_{\mathrm{f}} 40 \%$ waktu oflkalicetrjalmeed and Reinforced Plastics and Electrical Insulating Materials1 ", ASTM, 2002.

Annual Book of Standards, D 5941 - 00 , "Standard Test Methods for Determining the Izod Pendulum Impact Resistance of Plastics”, ASTM, 2000.

Anonim, Manual Book of Izod Impact - Gotech

MEDIA MESIN, Vol. 11, No. 1, Januari 2010, 8 - 14 
Anonim, 2001,Technical data Sheet,PT Justus Sakti Raya Corporation, Jakarta.

Aziz, S.H., Martin, P, Ansell, 2003, The effect of alkalization and fibre alignment on the mechanical and thermal properties of kenaf and hemp bast fibre composites, Department of Engineering and Applied Science, University of Bath, Bath BA2 7AY, $U K$.

Jamasri, 2008, Prospek Pengembangan Komposit Serat Alam Di Indonesia, Pengukuhan Jabatan Guru besar, Fakultas Teknik, Universitas Gadjah Mada.

Marsahyo E., Soekrisno, Jamasri, Rochardjo H.S.B., 2005. “ Kajian Mikromekanika Bahan Komposit Serat Ramie-Epoxy”, Disertasi Doktor (dalam proses penyelesaian), UGM, Yogyakarta.

Nugraha, I.N.P., Marsyahyo, E., Rochardjo, H.S.B., 2005, “Pengaruh Perlakuan Kimia pada Serat Alam Ramie terhadap Kekuatan tarik Serat Tunggal”, paper paper Seminar nasional Perkembangan Riset dan Teknologi bidang Industri, Universitas Gadjah Mada, 18-19 Mei 2005, Jogjakarta.

Peijs, T., 2002, Composites turn green, Department of Materials, Queen Mary, University of London.

Sudiro.D., 2004, Rami Tanaman Asli Indonesia Untuk Meningkatkan Kemandirian Kebutuhan Alat Pertahanan, Buletin Balitbang STT No2289 volume VII nomor 13.

Shackelford, 1992. "Introduction to Materials Science for Engineer”, Third Edition, MacMillan Publishing Company, New York, USA. 